\title{
Coarctation of the aorta life and health $20-44$ years after surgical repair
}

\author{
A B Stewart, R Ahmed, C M Travill, C G H Newman
}

\begin{abstract}
Objective-To examine the health and lifestyle of a group of patients who had repair of coarctation of the aorta 20-44 years ago (these were the first such operations in the United Kingdom) and to see how the results would influence current management strategies.

Design-Attempts were made to contact all patients by questionnaire. They were then requested to attend for a clinical examination.

Setting-Patients had their initial surgery at the Westminster Hospital (by Charles Drew) and the follow up examination at the same hospital.

Patients-149 operations were performed. 70 of the 106 patients presumed to be alive were traced and 62 replied. 42 attended for examination. Only patients with the diagnosis of simple coarctation were included. Some patients had had coincidental ligation of a patent ductus arteriosus but none had any other cardiac abnormality requiring surgical or medical treatment. Those who died during the follow up period were described in paper by Bobby et al (Br Heart J 1991;65:271-6).
\end{abstract}

Main outcome measures-Current symptoms and life situations, evidence of cardiac disease, further cardiac surgery, current and retrospective blood pressures, and Doppler echocardiographic examination.

Results-29 (69\%) had cardiovascular disorder. Doppler echocardiography did not show previously unrecognised major recoarctation. $19(46 \%)$ had hypertension at follow up and there was evidence of enlargement of the aortic root or arch in seven $(16 \%)$ patients, who tended to have had surgery at a later age. No evidence of cerebrovascular accident was found.

Conclusions-In this group of patients with surgically repaired simple coarctation, late morbidity (particularly aortic aneurysm, aortic valve disease, and ischaemic heart disease) was common. The incidence of intracranial haemorrhage seemed to have been reduced by surgical repair. The integrity of the surgery remained good. Many patients did not have any regular cardiovascular review. Long-term anxiety related to early surgical experiences was evident. Even after apparently successful surgical

repair of aortic coarctation. It would be prudent for all patients to have long-term review.

(Br Heart J 1993;69:65-70)

Coarctation of the aorta without an associated lesion is a deceptively simple condition. It seems at first sight to be a condition limited to a distinct part of the aorta where it is amenable to surgical correction. Several studies, however, showed that though patients benefit from operation their life expectancy is considerably reduced and they are at increased risk of various linked and potentially disabling conditions. ${ }^{1-3}$

The first coarctation repair was performed by Crafoord in 1945. Shortly afterwards Sir Clement Price-Thomas and Mr Charles Drew performed the first operation of this type in the United Kingdom, at the Westminster Hospital. Many patients who had coarctation surgery 20, 30 and $40+$ years ago are now appearing in adult clinics. The purpose of this study was to evaluate at long-term follow up the current health and lifestyle of a group of patients who had had coarctation repair up to 44 years ago and determine whether or not their current condition could identify risk factors for late problems that might influence or support current management strategies.

In the early days surgical repair was restricted to adult patients but with increasing experience and confidence surgery was extended to children. With wider practice of the operation a consensus arose that all patients with coarctation should be offered surgical relief in early childhood. ${ }^{5}$ Reluctance to operate at a very early age was initially based on technical difficulties and the tendency for the narrowing to recur after surgery on very small vessels. Later, especially after the introduction of the subclavian flap technique, surgical confidence grew and repairs were undertaken on ever younger patients so that repair now takes place soon after diagnosis, irrespective of age, but taking into account the risk of recoarctation which is commoner after early surgery. ${ }^{67}$

\section{Patients and methods}

We reviewed the records of all patients who underwent coarctation repair at the Westminster Hospital from 1946-70. Those patients still living who could be traced were sent a questionnaire. In addition patients were invited to attend the Westminster Hospital for a further assessment by a clinical examination including blood pressure measurement (taken from the right arm with an appropriately sized
Horseferry Road, Londo SW1P 2AP.

Accepted for publication 30 June 1992. 
Figure 1 Continuous wave Doppler display showing double image. $V_{1}$, pre-coarctation velocity $(\mathrm{m} / \mathrm{s})$ with derived gradient $(\mathrm{mm} \mathrm{Hg}) ; \mathrm{V}_{2}$, post-coarctation velocity $(\mathrm{m} / \mathrm{s})$ with derived gradient $(\mathrm{mm} \mathrm{Hg}$ ).

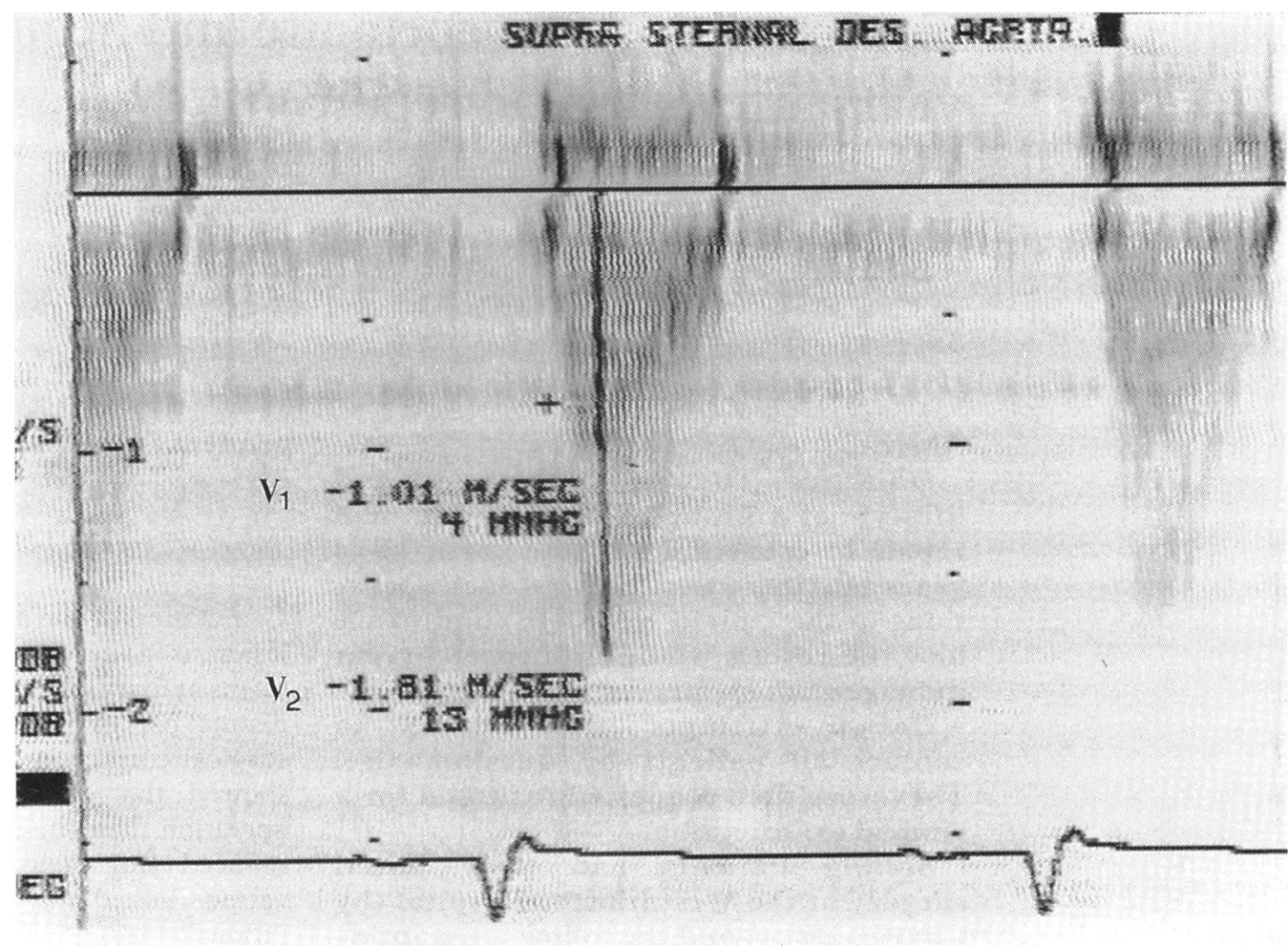

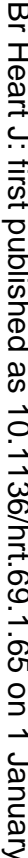

cuff), a posteroanterior chest $\mathrm{x}$ ray, an electrocardiogram, and Doppler echocardiography performed on an Interspec XL machine with a stand alone $2.0 \mathrm{MHz}$ continuous wave Doppler probe. Doppler velocities were measured in the ascending and descending aorta by continuous wave Doppler. We used the modified Bernoulli equation to calculate the residual gradient: gradient $(\mathrm{mm} \mathrm{Hg})=4\left(\mathrm{~V}_{2}^{2}-\mathrm{V}_{1}^{2}\right) \mathrm{m} / \mathrm{s}$, where $\mathrm{V}_{2}$ was the maximum velocity in the descending aorta and $V_{1}$ was the velocity in the descending aorta above the coarctation site when a double shadow could be obtained on Doppler tracing (see fig 1 ) or $V_{1}$ was the velocity in the ascending aorta when a suitable tracing was not obtained. This method is similar to the method reported by Aldousahy et $a l^{8}$ who also used Doppler methods to assess recoarctation. For statistical analysis we used paired $t$ tests.

\section{Results}

From 1946 to 1970,149 operations were performed at the Westminster Hospital for repair of coarctation of the aorta. This included some patients with an associated patent ductus arteriosus that was ligated but none in this group had any other associated abnormalities that required operation or continued medical treatment. In this group there were 20 early deaths (in the first three months after surgery) and a further 23 patients are known to have died subsequently. ${ }^{1}$ Seventy of the remaining 106 were traced. The remaining 36 who were not traced were patients from abroad, patients with insufficient details, and possibly some others who had died.

Seventy patients were sent a questionnaire designed to give a subjective assessment of health, lifestyle, and symptoms. They were asked to give details of other cardiovascular disease and surgery. Sixty two patients replied and 42 agreed to attend for further assessment $\overrightarrow{0}$ at the Westminster Hospital (table 1). The questionnaires and available data indicate that $\sigma$ apart from geographical distance the patients seen were a representative sample of those contacted.

QUESTIONNAIRE AND HISTORY IN 62 PATIENTS Subjective opinions

Most people did not feel that their heart surgery had had a deleterious effect on their lives. Eight, however, felt that their condition $\overrightarrow{\mathbb{Q}}$ or operation had had a negative effect on their $\stackrel{\Xi}{2}$ education, and two considered their heart sur- $\dot{0}$ gery had contributed to a reluctance to have children. Only two were unemployed and three thought they may not have been considered for a job because of their medical history. Several 은 had been refused entry to the armed forces. $\rightarrow$ They had a wide range of occupations-from merchant banker and solicitor to refuse collec- $N$ tor and unskilled manual worker. Eleven had $N$ been asked to pay increased life insurance N premiums.

Table 1 Details of groups of patients studied

\begin{tabular}{|c|c|c|}
\hline & $\begin{array}{l}\text { Questionnaire } \\
\text { only } \\
(n=62)\end{array}$ & $\begin{array}{l}\text { Questionnaire } \\
\text { and examination } \\
(n=42)\end{array}$ \\
\hline $\operatorname{Sex}(M / F)$ & $41 / 21$ & $28 / 14$ \\
\hline $\begin{array}{l}\text { Age at follow up (yr): } \\
\text { Range } \\
\text { Mean (SD) }\end{array}$ & $\begin{array}{l}22-69 \\
41 \cdot 4\end{array}$ & $\begin{array}{l}22-68 \\
41 \cdot 4\end{array}$ \\
\hline $\begin{array}{l}\text { Duration of follow up }(\mathrm{yr}) \text { : } \\
\text { Range } \\
\text { Mean }\end{array}$ & $\begin{array}{l}21-43 \\
29 \cdot 9\end{array}$ & $\begin{array}{l}21-42 \\
29 \cdot 8\end{array}$ \\
\hline $\begin{array}{l}\text { Age at operation }(\mathrm{yr}) \text { : } \\
\text { Range } \\
\text { Mean } \\
<1 \mathrm{yr} \\
1-10 \mathrm{yr} \\
11-20 \mathrm{yr} \\
>20 \mathrm{yr}\end{array}$ & $\begin{array}{l}1 \mathrm{mnth}-45 \mathrm{yr} \\
11 \cdot 9 \mathrm{yr} \\
8 \\
24 \\
13 \\
17\end{array}$ & $\begin{array}{l}1 \mathrm{mnth}-45 \mathrm{yr} \\
12 \cdot 2 \mathrm{yr} \\
6 \\
15 \\
11 \\
10\end{array}$ \\
\hline
\end{tabular}


Four expressed continued and unsubstantiated anxiety relating to their coarctation surgery. A further five had concerns related directly to their operation. Of these, three patients were very anxious about the appearance of their scar even up to 42 years after surgery; one queried a link between early surgery and depression in later life and one who had surgery aged 14 years and had had to return to the operating theatre because of bleeding within a few hours said she had only finally come to terms with her experience 23 years later. Eighteen $(29 \%)$ were smokers.

\section{Health}

All but eight considered themselves to be in good health. Forty three patients $(69 \%)$ were symptom free (NYHA class I), $16(26 \%)$ had mild symptoms (NYHA class II), two (3\%) had significant exercise dyspnoea (NYHA class III), and one $(2 \%)$ was severely disabled (NYHA IV).

Four were taking regular antihypertensive medication (two with digoxin and diuretics), two took regular glyceryl trinitrate, and two were taking anticoagulants.

There were no new cerebrovascular accidents although one patient had had a stroke related to mitral valve surgery after anticoagulants had been inadvertently stopped and another had had a transient ischaemic attack related to severe aortic stenosis.

\section{Regular review}

Only $34(55 \%)$ attended a hospital for regular review of their cardiovascular system. These were mostly patients who had represented with a new problem rather than for follow up of their coarctation.

\section{Further cardiovascular surgery}

Four $(6 \%)$ had required further surgery for recoarctation. Three of these had had their primary repair in the first two months of life and the other at the age of two. Four had required aortic valve replacement, three coronary artery bypass grafts, and one a mitral valvotomy. Two further patients had severe aortic regurgitation and were waiting to have an aortic valve replacement. One had had a successfully treated episode of endocarditis of the aortic valve. Altogether $14(22.5 \%)$ out of $62 \mathrm{had}$ undergone, or were awaiting, further cardiac surgery.

\section{Family history}

Three (4\%) (including a father and son in the study group) had had children with coarctation and one had a son with a bicuspid aortic valve. Two of our patients were sisters.

\section{CLINICAL EXAMINATION IN 42 PATIENTS}

All the peripheral pulses were regular, two were collapsing, and in all except one patient, who had sinus bradycardia, the rate was normal. All patients had palpable femoral pulses with no significant radiofemoral delay. Two had impalpable foot pulses. In 26 auscultation showed systolic murmurs. These were aortic ejection murmurs in 24 and only one was
Table 2 Blood pressure classification at follow up by Joint Committee Report 1988 (JNC 4)

\begin{tabular}{lcc}
\hline Classification & No & $\%$ \\
\hline $\begin{array}{l}\text { Normotensive } \\
\text { (diastolic BP <90 mm Hg) }\end{array}$ & 23 & 54 \\
$\begin{array}{l}\text { Mild hypertension } \\
\text { (diastolic BP 90-104 mm Hg) }\end{array}$ & 16 & 40 \\
$\begin{array}{l}\text { Moderate hypertension } \\
\text { (diastolic BP 105-114 mm Hg) }\end{array}$ & 1 & 2 \\
$\begin{array}{l}\text { Severe hypertension } \\
\text { (diastolic BP > 115 mm Hg) }\end{array}$ & 0 & 0 \\
$\begin{array}{l}\text { Isolated systolic hypertension } \\
\text { (systolic BP > 160 mm Hg) }\end{array}$ & 2 & 4 \\
\hline
\end{tabular}

associated with a thrill. In addition there was one murmur of mitral incompetence and one murmur of a ventricular septal defect. There were also four patients with aortic diastolic murmurs and one with signs of mitral stenosis.

Blood pressure measurements were mean (SD) systolic (139.1 (14) $\mathrm{mm} \mathrm{Hg}$ ) and mean diastolic $(84.2(14.4) \mathrm{mm} \mathrm{Hg})$. According to JNC $-4{ }^{9}$ criteria for hypertension, $16(40 \%)$ had mild hypertension (diastolic BP 90-104 $\mathrm{mm} \mathrm{Hg}$ ), one ( $2 \%$ ) had moderate hypertension (diastolic BP 105-114 mm Hg), and two (4\%) had isolated systolic hypertension (systolic BP $>160 \mathrm{~mm} \mathrm{Hg}$ ) (table 2).

Electrocardiograms were normal in only 12 (25\%): there was evidence of ischaemia in nine, left ventricular hypertrophy in three); minor conduction defects (incomplete right bundle branch block in 12, complete right bundle branch block in four, and sinus bradycardia in one.

Chest $x$ rays were normal in $16(n=33)$. In eight there was cardiomegaly with a cardiothroacic ratio greater than 0.5 (range $0.39-0.96$ ). Widening or tortuosity of the descending aorta or arch was seen in four and other abnormalities found included prominence of the left subclavian artery in two, calcification of the aorta in one, pulmonary calcification in one, and hilar lymphadenopathy in one.

Echocardiography and Doppler studies showed bicuspid aortic valves in $11(26 \%)$. One bicuspid valve was severely stenosed (Doppler derived gradient $70 \mathrm{~mm} \mathrm{Hg}$ ). Whereas the others were mildly or not at all stenosed (Doppler derived gradients: range 3-14 $\mathrm{mm} \mathrm{Hg}$ and mean $9.5 \mathrm{~mm} \mathrm{Hg}$ ). Two patients (both awaiting aortic valve replacement) had severe aortic regurgitation and two were considered to have mild aortic regurgitation. A further four had prosthetic aortic valves.

Three had dysplastic mitral valves including one with recurrence of severe mitral stenosis. There was one small ventricular septal defect and one left-sided superior vena cava draining to the coronary sinus.

The mean diameter of the aortic root was $2.9 \mathrm{~cm}$ (range $2 \cdot 2-4.9 \mathrm{~cm}$, normal $2.0-3.7 \mathrm{~cm}$ ). One had had acute aortic root dilatation in the immediate postpartum period associated with the development of sudden aortic incompetence and was awaiting aortic valve replacement. Another had a prosthetic aortic valve in situ. The other was symptom free with no aortic incompetence. One patient had significant septal hypertrophy consistent with early hypertrophic cardiomyopathy. 
The mean (SD) Doppler gradient across the coarctation site was $9 \cdot 1 \mathrm{~mm} \mathrm{Hg} \mathrm{(8.7)} \mathrm{(range} \mathrm{0-}$ $28 \mathrm{~mm} \mathrm{Hg}$ ) and only one patient, with a gradient of $8 \mathrm{~mm} \mathrm{Hg}$, had slight prolongation of the trace into diastole which suggests a more considerable gradient than the direct measurement. ${ }^{10}$

\section{Discussion}

We reviewed the quality of life and cardiovascular morbidity of a group of patients treated surgically for coarctation of the aorta who were followed up for up to 44 years. The main aim of the study was to attempt to identify factors that could be favourably influenced by altering the way that patients with coarctation of the aorta are currently managed.

\section{QUESTIONNAIRE}

Two thirds of patients reported no cardiac symptoms and most were leading normal lives in employment, were married, and in many cases had had children. The fact that nine $(21 \%)$ volunteered anxieties associated with their coarctation surgery suggested persistent psychological morbidity. Postoperative counselling was not a feature of the care of these patients. This attitude may have denied the parents of the patients the opportunity to discuss their concerns. Three of the four patients who expressed continuing anxiety about their heart had had repeat operation for recoarctation at the ages of six, 16, and 16 years. Clearly patients who required repeat surgery were especially vulnerable and further effort should be directed to give them the opportunity for full discussion.

\section{RECOARCTATION}

Up to 42 years after operation the integrity of the initial surgery was sound. No recurrence of serious recoartation was detected by Doppler examination at the coarctation site but three patients had peak gradients $>25 \mathrm{~mm} \mathrm{Hg}$ (maximum $28 \mathrm{~mm} \mathrm{Hg}$ ) that required review and further assessment. Doppler gradients across the coartation site represent the maximum instantaneous gradient rather than the peak to peak gradient as conventionally measured by cardiac catheterisation. ${ }^{11}$ But even when these differences are taken into account some Doppler measurements still misrepresent the severity of obstruction to flow. ${ }^{12}$ Factors such as the length of the narrowed segment, the presence of an extensive collateral circulation, and the stroke volume all affect the Doppler derived gradient. The additional assessment of diastolic flow velocity decay ${ }^{10}$ has been shown to improve the accuracy of Doppler derived gradients. Exercise induced gradients would also provide further useful information.

In this group the maximum pressure drop was $28 \mathrm{~mm} \mathrm{Hg}$ without diastolic flow prolongation which can reasonably be interpreted as a good result. All traces were examined for prolongation of the flow into diastole as evidence of more severe obstruction. ${ }^{10}$ Only one had evidence of a slightly prolonged flow.

Four $(9.5 \%)$ had had surgery for recoarctation. This is a similar recurrence rate to other studies. ${ }^{3}$ In these cases operation was performed at a mean of 11 years after primary repair and the eldest patient was 16 years old at the time of repeat operation.

As in other studies ${ }^{67}$ those who were young at the time of primary repair were more likely to have recoarctation. The lack of any late major recoarctation suggested that narrowing was a $\frac{T}{D}$ result of the patient's growth rather than of scarring and fibrosis alone and shows that the $\varsigma$ end to end anastamosis can have satisfactory long-term results.

This long-term follow up showed that beyond the growing years the risk of recoartation was small. The influence of exercise on gradients that were small at rest was not assessed, however.

\section{AORTIC VALVE ABNORMALITIES}

The association between coarctation and bicuspid aortic valves becomes increasingly impor- of tant with age. ${ }^{13}$ Fifteen patients $(36 \%)$ had abnormal aortic valves: eight were bicuspid of with little or no aortic stenosis shown on ㅇ Doppler echocardiograms, three with considerable haemodynamic disturbance (two were severely incompetent and the patients were awaiting replacement and one was severely stenotic), and four had already been $\vec{\theta}$ replaced. Thus one in six patients with coarct- 8 ation of the aorta developed significant aortic valve disease on long-term follow up though an abnormal aortic valve ("trivial aortic incompetence") was noted in only one patient at the time of coarctation surgery. Post mortem studies $^{14}$ suggested that at least $1 \%$ of the population have bicuspid aortic valves. Such valves are unlikely to cause problems, especially in early life. Calcification of the aortic valve becomes more common ${ }^{15}$ from the fourth decade and a high percentage of patients who are given aortic valve replacement are found to have bicuspid valves that are stenotic, regurgitant, or damaged by endocarditis. This high rate of important aortic valve disease supports the need for regular and long-term review of apparently well patients.

\section{HYPERTENSION}

Late hypertension can develop. ${ }^{236}$ In our series $N$ $46 \%$ of patients were hypertensive at follow up. N Paired $t$ tests showed a significant fall in blood pressure when preoperative and postoperative values were compared but no significant difference between postoperative and follow up results. Cohen et al ${ }^{6}$ reported that age at initial 0 repair was the most important predictor of $\frac{\vec{D}}{\mathbb{D}}$ hypertension. In our series, however, there was no statistically significant difference in blood

$\begin{aligned} & \text { Table } 3 \\
& \text { follow up }\end{aligned}$
\begin{tabular}{lll} 
Age at initial & Number of patients & Hypertension at \\
repair $(y r)$ & $(\%)$ & follow up $(n(\%))$ \\
\hline$<1$ & $6(14)$ & $3(50)$ \\
$1-9$ & $15(35)$ & $5(33)$ \\
$10-19$ & $12(29)$ & $7(58)$ \\
$20+$ & $9(22)$ & $4(44)$ \\
\hline
\end{tabular}


Table 4 Radiographic and echocardiographic evidence of abnormally widened aorta

\begin{tabular}{lllll}
\hline \multirow{2}{*}{$\begin{array}{l}\text { Case } \\
\text { No } \begin{array}{l}\text { Age at } \\
\text { operation } \\
(y r)\end{array}\end{array}$} & \multicolumn{3}{l}{ Blood pressure $(\mathrm{mm} \mathrm{Hg})$} \\
\cline { 2 - 5 } & Preoperative & Postoperative & Follow up \\
\hline $1^{\star}$ & 2 & $160 / 90$ & $120 / 80$ & $150 / 80$ \\
$2 \dagger$ & 8 & $170 / 120$ & $125 / 80$ & $128 / 80$ \\
3 & 29 & $195 / 120$ & & $138 / 85$ \\
4 & 24 & $150 / 75$ & $120 / 65$ & $135 / 85$ \\
5 & 28 & $198 / 98$ & $150 / 90$ & $150 / 90$ \\
6 & 15 & $150 / 80$ & $130 / 90$ & $130 / 90$ \\
7 & 32 & $160 / 110$ & $129 / 81$ & $145 / 90$ \\
Mean & $19 \cdot 7$ & $169 / 99$ & $129 / 81$ & $139 / 86$ \\
\hline
\end{tabular}

Significant aortic

pressure at follow up between those operated on before 10 years (table 3 ).

Preoperative hypertension was common. Only five $(13 \%)$ patients were normotensive with blood pressure lower than the 90th centile for age. At follow up two were normotensive and three hypertensive.

Eleven $(40 \%)$ of the 27 patients in whom blood pressure recordings at time of discharge after operation were available were normotensive ( $<90$ th centile for age) and seven $(64 \%)$ of them remained normotensive at late follow up. Half of those who were normotensive at follow up, however, had been normotensive after operation and half had been hypertensive. In this group therefore there was no relation between perioperative hypertension and subsequent hypertension at late follow up, though such a relation was reported in other studies. ${ }^{26}$

\section{AORTIC ANEURYSM}

The late development of aortic aneurysm has been reported in other series as a cause of mortality ${ }^{136}$ and we suggest that the aortic wall may be irreversibly damaged in the preoperative period when the aorta proximal to the coarctation is subject to high distending forces. This would be more likely in patients who are operated on late and in whom systolic blood pressure is high. In our group the mean age of those with echocardiographic or $x$ ray evidence of an abnormally widened aorta was not significantly different from the group as a whole but there was a trend for these patients to have had surgery late (table 4).

Five of the six patients from the same cohort who subsequently died ${ }^{1}$ from rupture of aortic aneurysms were operated on when they were more than 10 years old (mean 19.6 years) (table 5 ). The current practice of early operation may reduce the likelihood of the long-term development of aortic aneurysms. This will only be evident with time.

Table 5 Details of six patients who died after aortic rupture

\begin{tabular}{llll}
\hline Case No. & $\begin{array}{l}\text { Age at } \\
\text { operation } \\
(y r)\end{array}$ & $\begin{array}{l}\text { Preoperative } \\
\text { blood pressure } \\
(\text { mm Hg) }\end{array}$ & $\begin{array}{l}\text { Age at death } \\
(y r)\end{array}$ \\
\hline 1 & 25 & $170 / 110$ & 56 \\
2 & 30 & $210 / 110$ & 41 \\
3 & 10 & & 33 \\
4 & 18 & & 25 \\
5 & 30 & $170 / 110$ & 39 \\
6 & 5 & - & 20 \\
Mean & $19 \cdot 6$ & - \\
\hline
\end{tabular}

Table 6 Evidence of ischaemic heart disease at late follow up

\begin{tabular}{lll}
\hline $\begin{array}{l}\text { Age at } \\
\text { operation } \\
(y r)\end{array}$ & Evidence of IHD & $\begin{array}{l}\text { Follow up } \\
\text { BP } \\
(\mathrm{mm} \mathrm{Hg})\end{array}$ \\
\hline 23 & Coronary bypass graft (aged 44 yr) & $140 / 96$ \\
18 & Coronary bypass graft (aged 46 yr) & $160 / 94$ \\
37 & Coronary bypass graft (aged 67 yr) & $158 / 80$ \\
19 & ECG & $124 / 80$ \\
8 & ECG & $128 / 80$ \\
8 & ECG & $110 / 76$ \\
14 & ECG & $135 / 80$ \\
32 & ECG & $145 / 90$ \\
18 & ECG & $140 / 90$ \\
21 & ECG & $120 / 70$ \\
Mean $19 \cdot 8$ & & \\
\hline
\end{tabular}

IHD, ischaemic heart disease; BP, blood pressure.

In no case was the dilatation directly associated with the site of coarctation repair. This could imply that the late formation of aortic aneurysms is not as a direct consequence of the type of repair undertaken but rather part of the more generalised disease process. Aortoplasty with Dacron or other artificial patch was reported to be associated with aneurysm formation at the site of repair, ${ }^{16}$ however, there were no such operations in this group. Late examination with magnetic resonance imaging would be a more accurate way of detecting aneurysm formation. ${ }^{17}$

\section{CEREBRAL HAEMORRHAGE}

Late cerebral haemorrhages were common in a study of the course of unoperated coarctation. ${ }^{1819}$ None of the patients we studied had had strokes or subarachnoid haemorrhage after operation $^{1}$ (two had subarachnoid haemorrhage preoperatively). Nor did any of the patients who died (table 5). The reasons for this are not apparent but this result could imply that coarctation repair in some way protects against the surges of excessively high blood pressure that cause bleeding from associated arterial wall defects in the circle of Willis.

\section{ISCHAEMIC HEART DISEASE}

There was evidence of ischaemic heart disease in 10 patients ( $23 \%$ ): three had had disease that was severe enough to require coronary artery bypass graft surgery. Table 6 shows the details of these patients and their follow up blood pressure and age at repair of coarctation and age of coronary artery surgery. As with others in this group primary repair was performed at a late age (mean 19.8 years) but only four were hypertensive at the time of examination. This accords with the high incidence of coronary artery disease reported in other series. ${ }^{20}$

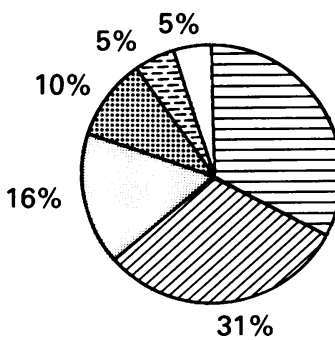

$33 \%$

目 Hypertension
$\square$ Normal
$\square$ Aortic valve
disease
Ischaemic heart
disease
Aortic dilatation
$\square$ Other cardiac

Figure 2 Major cardiac morbidity groups at follow up $(n=42)$. 


\section{OVERALL MORBIDITY}

At long-term follow up only $13(31 \%)$ were free of evidence of cardiovascular morbidity. When patients are assigned to their major abnormality group 14 had hypertension, four ischaemic heart disease, seven aortic valve disease, two arotic root dilatation, and two had other cardiac structural abnormalities (fig 2). This is a considerable burden of cardiac disease in a group with a mean age of 41 years.

\section{CONCLUSION}

Coarctation of the aorta is an apparently simple defect that can be surgically repaired. Though a successful surgical technique was established nearly 50 years ago, the risk of long-term morbidity remains high with excess mortality. Though the management of coarctation has changed over the years, especially in relation to the optimal age for surgical repair, and this makes direct comparisons difficult, it is evident that long-term follow up of all cases deserves more attention than it receives. The development of aortic aneurysms continues to cause concern as does the incidence of ischaemic heart disease, aortic valve disease, and hypertension, all of which affect a relatively young adult population. Our study indicates that clinical and Doppler echocardiographic examination may need to be supplemented by electrocardiography and perhaps magnetic resonance imaging of the aortic arch. Continued long-term review of all cases is indicated.

We thank Dr Kevin Walsh, Miss Clare Jenkins, and Miss Jacqui Bobby for their contribution the initial research; Dr Richard Sutton, Mrs S White, Mrs S Williams, and the Cardiology Department Westminster Hospital for their assistance; Mr Dorothy Taylor for clerical and secretarial help; and Miss Joan Smith for scrupulous record keeping. The Garfield Weston Trust gave some of the funding.
1 Bobby J, Emami JM, Farmer RDT, Newman CGH. Operative survival and 40 year follow up of surgical repair of aortic coarctation. Br Heart J 1991;65:271-6.

2 Maron J, Humphries JO, Rowe RD, Mellits ED. Prognosis of surgically Corrected Coarctation of the Aorta. Circulation 1973;47:119-26.

3 Presbitero $P$, Demarie $D$, Villani $M$, et al. Long term results 15-30 years) of surgical repair of aortic coarctation. $\mathrm{Br}$ Heart $J$ 1987;57:462-7.

4 Crafoord C, Nylan G. Congenital coarctation of the aorta and its surgical treatment. J Thorac Surg 1945;14:347-61.

5 Koller M, Rothlin M, Senning A. Coarctation of the aorta: review of 362 operated patients. Long term follow-up and review of 362 operated patients. Long term follow-up and 8:670-9.

6 Cohen M, Fuster V, Steele P, Driscoll D, McGoon C. Coarctation of the aorta long-term follow-up and prediction of outcome after surgical correction. Circulation 1989;80:840-5.

7 Schuster S, Gross R. Surgery for coarctation of the aorta: A review of 500 cases. J Thorac Cardiovasc Surg 1962;43: 54-70.

8 Aldousahy W, DiSessa TG, Alpert BS, Birnbaum SE, Willey ES. Significance of the Doppler-derived gradient across a residual aortic coarctation. Pediatr Cardiol 1990; 11:8-14.

9 JNC4. Joint National Committee Report. Arch Intern Med 1988;148:1023-38.

10 Carvalho JS, Redington AN, Shinebourne EA, Rigby ML Gibson D. Continuous wave Doppler echocardiography and coarctation of the aorta; gradients and flow patterns in the assessment of severity. Br Heart $J 1990 ; 64: 133-7$.

11 Currie PJ, Hagler DJ, Steward JB. Instantaneous pressure gradient: a simultaneous Doppler and dual catheter correlative study. J Am Coll Cardiol 1986;7:800-6.

12 Houston AB, Simpson IA, Pollock JSC, Jamieson MPG, Doig WB, Coleman EN. Doppler ultra sound in the assessment of severity of coarctation of the aorta and interruption of the aortic arch. Br Heart J 1987;57:38-43.

13 Simon $A B$, Zloto $A E$. Coarctation of the Aorta Longitudina Assessment of Operated Patients. Circulation 1974;50: 456-64.

14 Roberts W. The congenitally bicuspid aortic valve. $A m J$ Cardiol 1970;26:72-83.

15 Campbell $M$. Calcific aortic stenosis and congenital bicuspid aortic valves. Br Heart J 1968;30:606.

16 Bergdahl L, Ljungquist A. Long term results after repair of coarctation of the aorta by patch grafting. $J$ Thorac Cardiovasc Surg 1980;80:177-81.

17 Rees S, Somerville J, Ward C, et al. Coarctation of the aorta: MR imaging in late postoperative assessment. Radiology 1989;173:499-502.

18 Campbell $\mathrm{M}$, Bayliss $\mathrm{JH}$. The course and prognosis of coarctation of the aorta. Br Heart J 1956;18:475-95.

19 Campbell $M$. Natural history of coarctation of the aorta. Br Heart J 1970;32:633-40.

20 Clarkson P, Nicholson M, Barrat-Boyes B, Neutze J, Whitlock R. Results after repair of coarctation of the aorta beyond infancy: A 10 to 28 year follow-up with particular beyond infancy: A 10 to 28 year follow-up with particular 1983;51:1481-8. 